A. Rout and K. Binnemans, Dalton Transactions 44, 1379-1387 (2015).

\title{
Influence of the ionic liquid cation on the solvent extraction of trivalent rare-earth ions by mixtures of Cyanex 923 and ionic liquids
}

\author{
Alok Rout ${ }^{\mathrm{a}}$ and Koen Binnemans ${ }^{\mathrm{a} *}$ \\ ${ }^{a}$ KU Leuven, Department of Chemistry, Celestijnenlaan 200F, P.O. Box 2404, B-3001 \\ Heverlee (Belgium). \\ * Corresponding author: \\ E-mail: Koen.Binnemans@chem.kuleuven.be
}

Phone: +3216327446

Fax: +3216327992 


\begin{abstract}
Trivalent rare-earth ions were extracted from nitric acid medium by the neutral phosphine oxide extractant Cyanex 923 into ionic liquid phases containing the bis(trifluoromethylsulfonyl)imide anion. Five different cations were considered: 1-butyl3-methylimidazolium, 1-decyl-3-methylimidazolium, methyltributylammonium, methyltrioctylammonium and trihexyl(tetradecyl)phosphonium. The extraction behavior of neodymium(III) was investigated as a function of various parameters: $\mathrm{pH}$, extractant concentration, concentration of the neodymium(III) ion in the aqueous feed and concentration of the salting-out agent. The loading capacity of the ionic liquid phase was studied. The extraction efficiency increased with increasing $\mathrm{pH}$ of the aqueous feed solution. The extraction occurred for all ionic liquids via an ion-exchange mechanism and the extraction efficiency could be related to the solubility of the ionic liquid cation in the aqueous phase: high distribution ratios for hydrophilic cations and low ones for hydrophobic cations. Addition of nitrate ions to the aqueous phase resulted in an increase in extraction efficiency for ionic liquids with hydrophobic cations due to extraction of neutral complexes. Neodymium(III) could be stripped from the ionic liquid phase by $0.5-$ 1.0 M nitric acid solutions and the extracting phase could be reused. The extractability of other rare earths present in the mixture was compared for the five ionic liquids.
\end{abstract}

Key words: ionic liquids; lanthanides; liquid-liquid extraction; neodymium; rare earths; solvent extraction 


\section{INTRODUCTION}

Ionic liquids (ILs) are alternatives for conventional diluents in solvent extraction processes. ${ }^{1-7}$ Since ionic liquids consist entirely of ions, they have a negligible vapor pressure and they are non-volatile. ${ }^{8,9}$ Replacement of volatile organic solvents in solvent extraction systems could lead to inherently safer extraction processes for metal ions. Many solvent extraction studies using ionic liquids as diluents and extractants have been carried out during the last 15 years. ${ }^{10-29}$ Ionic liquids that act as extractants can be considered as task-specific or functionalized ionic liquids. Most ionic liquids used as diluents contain either bis(trifluoromethylsulfonyl)imide or hexafluorophosphate anions. The bis(trifluoromethylsulfonyl)imide anion, $\left[\mathrm{Tf}_{2} \mathrm{~N}\right]^{-}$, is the preferred anion due to its better resistance to hydrolysis. ${ }^{30}$ The extraction mechanism for transfer of a metal from the aqueous to the organic phase can be different for ionic liquids compared to molecular solvents. Metal ions are typically extracted together with their counter anions by neutral extractants dissolved in a molecular diluents (= ion-pair mechanism or neutral mechanism), whereas in some ionic liquids extraction can also occur via an ion-exchange mechanism. This ion-exchange mechanism implies that ionic liquid cations are transferred from the organic phase to the aqueous phase during extraction of the metal ions. This ion-exchange mechanism for extraction of metal ions to an ionic liquid phase by neutral extractants has been well documented for extraction of alkali and alkaline earths metals by crown ethers. ${ }^{26,31-36}$ The extraction mechanism largely depends on the hydrophobic character of the ionic liquid: hydrophilic cations promote ion exchange, whereas hydrophobic cations suppress ion exchange. The hydrophobicity of the anion has an opposite effect: hydrophobic anions result in a greater tendency for cation 
exchange. ${ }^{37,38}$ The anion in the aqueous phase and its concentration have an effect on the mechanism, as evidenced by the extraction of $\mathrm{Na}^{+}, \mathrm{Sr}^{2+}$ and $\mathrm{Ba}^{2+}$ by crown ethers from $\mathrm{HNO}_{3}$ and $\mathrm{HCl}$ solution. ${ }^{39}$ A neutral crown ether nitrate complex is extracted from $\mathrm{HNO}_{3}$ solution, whereas chloride-based systems have a stronger tendency towards ion exchange. For extraction of anionic metal complexes by ionic liquids, there is also a competition between ion exchange and extraction of neutral complexes. Knowledge of the mechanism of a solvent extraction process based on ionic liquids is of importance, because it allows tuning processes to such an extent that no ionic liquid cations or anions are lost to the aqueous phase upon transfer of the metal ion to the ionic liquid phase..$^{40-42}$

Examples on extraction studies in ionic liquids using neutral extractants other than crown ethers are those on tributyl phosphate (TBP) and octyl(phenyl)- $N, N$ diisobutylcarbamoylmethyl phosphine oxide CMPO. ${ }^{11,43-50}$ Another example is Cyanex 923, which is an often used neutral extractant (solvating extractant) for solvent extraction of metal ions. ${ }^{51-62}$ The commercial Cyanex 923 extractant is a mixture of four trialkylphosphine oxides: $\mathrm{R}_{3} \mathrm{P}=\mathrm{O}, \mathrm{R}_{2} \mathrm{R}^{\prime} \mathrm{P}=\mathrm{O}, \mathrm{RR}_{2}^{\prime} \mathrm{P}=\mathrm{O}$ and $\mathrm{R}_{3}^{\prime} \mathrm{P}=\mathrm{O}$, where $\mathrm{R}=n$-octyl and $\mathrm{R}^{\prime}=n$-hexyl, and with an average molecular weight of $348 \mathrm{~g} \mathrm{~mol}^{-1} \cdot{ }^{63}$ Sun et al. described extraction with an imidazolium ionic liquid in combination with Cyanex 923 for the separation of yttrium from heavy rare earths in the presence of an aqueous complexant. ${ }^{64}$ Zhu et al. investigated the extraction of Sc(III) by Cyanex 923/[C $\left.\mathrm{C}_{8} \operatorname{mim}\right]\left[\mathrm{PF}_{6}\right]$ impregnated in a resin. ${ }^{65}$ Cyanex 925 , which has a composition similar to that of Cyanex 923 and consists mainly of bis(2,4,4-trimethylpentyl) octylphosphine oxide, was used in an ionic liquid for the separation of scandium from other rare earths. ${ }^{66}$ 
In this paper, we describe the liquid-liquid extraction of neodymium(III) and other trivalent rare-earth ions with Cyanex 923 in five ionic liquid diluents: 1-butyl-3methylimidazolium bis(trifluoromethylsulfonyl)imide $\left[\mathrm{C}_{4} \operatorname{mim}\right]\left[\mathrm{Tf}_{2} \mathrm{~N}\right]$, 1-decyl-3methylimidazolium bis(trifluoromethylsulfonyl)imide $\left[\mathrm{C}_{10} \operatorname{mim}\right]\left[\mathrm{Tf}_{2} \mathrm{~N}\right]$, methyltributylammonium bis(trifluoromethylsulfonyl)imide $\left[\mathrm{N}_{1444}\right]\left[\mathrm{Tf}_{2} \mathrm{~N}\right]$, methyltrioctylammonium bis(trifluoromethylsulfonyl)imide $\left[\mathrm{N}_{1888}\right]\left[\mathrm{Tf}_{2} \mathrm{~N}\right]$ and trihexyl(tetradecyl)phosphonium bis(trifluoromethylsulfonyl)imide $\left[\mathrm{P}_{66614}\right]\left[\mathrm{Tf}_{2} \mathrm{~N}\right]$. The aim of this systematic study was to investigate how the extraction mechanism depends on the type of ionic liquid cation and especially on the hydrophobicity of the cation.

\section{EXPERIMENTAL}

\section{Materials and reagents}

All chemicals and reagents used in this study were of analytical grade, and they were used as received without further purification. The ionic liquids: 1-butyl-3methylimidazolium bis(trifluoromethylsulfonyl)imide (> 98\%), methyltributylammonium bis(trifluoromethylsulfonyl)imide (> 98\%) and trihexyl(tetradecyl)phosphonium bis(trifluoromethylsulfonyl)imide (> 98\%) were purchased from IoLiTec (Heilbronn, Germany). 1-Decyl-3-methylimidazolium bis(trifluoromethylsulfonyl)imide and methyltrioctylammonium

bis(trifluoromethylsulfonyl)imide were synthesized following literature procedures. ${ }^{5,67}$ Sodium nitrate (99\%) and nitric acid were purchased from Sigma-Aldrich (Diegem, Belgium). Sodium hydroxide (98\%) was obtained from Alfa Aesar (Karlsruhe, 
Germany). Neodymium(III) nitrate hexahydrate and other rare-earth nitrate hydrates (purity > 99\%) were purchased from Acros Organics (Geel, Belgium). A 1000 ppm gallium standard was purchased from Merck (Overijse, Belgium). Cyanex 923 was kindly supplied by Cytec Industries, Canada.

\section{Instrumentation}

The concentrations of rare earths in the aqueous phase were determined with a bench top total reflection X-ray fluorescence (TXRF) spectrometer (S2 Picofox, Bruker). A Heraeus Megafuge 1.0 centrifuge was used for centrifugation of the samples after extraction. The viscosities of the ionic liquid phase were measured using an automatic Brookfield plate cone viscometer, Model LVDV-II+P CP (Brookfield Engineering Laboratories, USA).

$\mathrm{pH}$ measurements were performed with an S220 SevenCompact ${ }^{\mathrm{TM}} \mathrm{pH} / \mathrm{Ion}$ meter (Mettler-Toledo) and a Slimtrode (Hamilton) electrode. Luminescence spectra were recorded on an Edinburgh Instruments FS-920P spectrofluorimeter.

\section{Equilibration procedure}

The extraction experiments were performed at $30{ }^{\circ} \mathrm{C}$ with a temperature-controlled thermo-shaker (model: TMS - 200, Hangzhou Allsheng Instrument Co. LTD, China). The ionic liquid phases were pre-equilibrated with the desired concentration of nitric acid to fix the $\mathrm{pH}$. Extractions were performed by intensive shaking (2000 rpm) of the extraction mixture for $1.5 \mathrm{~h}$ (except for experiments on the time dependence of the extraction). After the extraction, separation of the phases was assisted by centrifugation for $5 \mathrm{~min}$ at $3000 \mathrm{rpm}$. The concentrations of neodymium distributed between the ionic 
liquid and the aqueous phases were measured by TXRF. The distribution ratio $(D)$ was determined using the following equation:

$$
\begin{aligned}
D & =\frac{[\mathrm{Nd}]_{\mathbb{L}}}{[\mathrm{Nd}]_{\mathrm{aq}}} \\
& =\frac{C_{\mathrm{i}}-C_{\mathrm{f}}}{C_{\mathrm{f}}} \times \frac{V_{a q}}{V_{L L}}
\end{aligned}
$$

$C_{\mathrm{i}}$ and $C_{\mathrm{f}}$ are the concentration of $\mathrm{Nd}(\mathrm{III})$ in the aqueous phase before and after extraction, respectively. Unless otherwise specified, $C_{\mathrm{i}}$ was $7 \times 10^{-4} \mathrm{M} \mathrm{Nd}(\mathrm{III}) . V_{a q}$ and $V_{I L}$ are the volumes of the aqueous and ionic liquid phase, respectively. A volume ratio of 1:1 was used for all the extraction experiments $\left(V_{a q}=V_{I L}\right)$. The extraction efficiency $(\% E)$ was determined using the following equation for $\left(V_{a q}=V_{I L}\right)$ :

$$
\% E=\frac{D}{D+1} \times 100
$$

The separation factor $\left(\alpha_{\mathrm{M} 1, \mathrm{M} 2}\right)$ was calculated as follows:

$$
\alpha_{M 1, M 2}=\frac{D_{M 1}}{D_{M 2}}
$$

$D_{M 1}$ and $D_{M 2}$ are the distribution ratios of the metal ions $M_{1}$ and $M_{2}$, respectively. The percentage stripping $(\% S)$ is defined by the equation:

$$
\% S=\frac{[M]_{\mathrm{aq}}}{[M]_{\mathrm{LL}}} \times 100
$$




\section{RESULTS AND DISCUSSION}

\section{Variation of equilibration time and $\mathbf{p H}$}

Neodymium(III) was extracted from a nitric acid solution by Cyanex 923 dissolved in the ionic liquids $\left[\mathrm{C}_{4} \mathrm{mim}\right]\left[\mathrm{Tf}_{2} \mathrm{~N}\right],\left[\mathrm{N}_{1444}\right]\left[\mathrm{Tf}_{2} \mathrm{~N}\right]$ and $\left[\mathrm{P}_{66614}\right]\left[\mathrm{Tf}_{2} \mathrm{~N}\right]$, with variation of different extraction parameters. For these experiments, a $\mathrm{Nd}(\mathrm{III})$ concentration of $7 \times 10^{-4} \mathrm{M}$ and a Cyanex 923 concentration of $0.1 \mathrm{M}$ was used. The volume ratio of the organic to the aqueous phase was $1: 1$. The temperature was $30{ }^{\circ} \mathrm{C}$. The first parameter that was varied was the equilibration time, in order to determine the time required to reach the equilibrium condition (Figure 1). Extraction was fastest for $\left[\mathrm{C}_{4} \mathrm{mim}\right]\left[\mathrm{Tf}_{2} \mathrm{~N}\right]$ and $\left[\mathrm{N}_{1444}\right]\left[\mathrm{Tf}_{2} \mathrm{~N}\right]$ : equilibrium was achieved within 30 to $40 \mathrm{~min}$. In case of $\left[\mathrm{P}_{66614}\right]\left[\mathrm{Tf}_{2} \mathrm{~N}\right]$, it took nearly $75 \mathrm{~min}$ to reach the equilibrium state. Thus in order to ensure reaching equilibrium conditions, the equilibration time of $1.5 \mathrm{~h}$ was used for all further extraction studies.

The distribution ratios $D$ increased with increasing $\mathrm{pH}$ for the extraction of Nd(III) by 0.1M Cyanex 923 diluted in ionic liquid diluents (Figure 2). An analogous trend had been observed by Sun et al. for the extraction of Y(III) from heavy rare-earth ions using Cyanex 923 in the ionic liquid $\left[\mathrm{C}_{8} \mathrm{mim}\right]\left[\mathrm{PF}_{6}\right] .{ }^{64}$ The $\mathrm{pH}$ dependence can be explained by the competition between the extraction of protons (or acid molecules) and the extraction of metal ions (or metal salts): neutral extractants are able to extract acids at low $\mathrm{pH}$ values. The distribution ratios depend on the type of ionic liquid: at all $\mathrm{pH}$ values, 
the distribution ratios for $\left[\mathrm{C}_{4} \mathrm{mim}\right]\left[\mathrm{Tf}_{2} \mathrm{~N}\right]$ and $\left[\mathrm{N}_{1444}\right]\left[\mathrm{Tf}_{2} \mathrm{~N}\right]$ are much higher than those for $\left[\mathrm{P}_{66614}\right]\left[\mathrm{Tf}_{2} \mathrm{~N}\right]$. Figure 3 shows the variation of the distribution ratio as a function of $\mathrm{pH}$ for the ionic liquids $\left[\mathrm{C}_{10} \operatorname{mim}\right]\left[\mathrm{Tf}_{2} \mathrm{~N}\right]$ and $\left[\mathrm{N}_{1888}\right]\left[\mathrm{Tf}_{2} \mathrm{~N}\right]$. When comparing these results with those presented in Figure 2, it can be observed that the $D$ values decrease with increase in the alkyl chain length. It should be noted that the $D$ values for $\left[\mathrm{N}_{1888}\right]\left[\mathrm{Tf}_{2} \mathrm{~N}\right]$ are higher than those for $\left[\mathrm{P}_{66614}\right]\left[\mathrm{Tf}_{2} \mathrm{~N}\right]$ at all $\mathrm{pH}$ values.

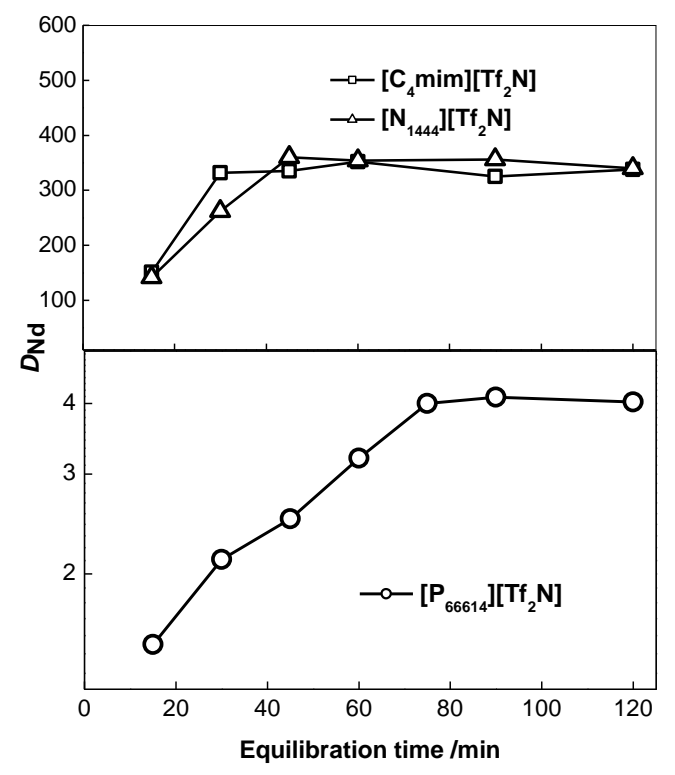

Figure 1. Variation of distribution ratio of $\mathrm{Nd}(\mathrm{III})$ as a function of the equilibration time, for extraction with Cyanex 923 in $\left[\mathrm{C}_{4} \operatorname{mim}\right]\left[\mathrm{Tf}_{2} \mathrm{~N}\right],\left[\mathrm{N}_{1444}\right]\left[\mathrm{Tf}_{2} \mathrm{~N}\right]$ or $\left[\mathrm{P}_{66614}\right]\left[\mathrm{Tf}_{2} \mathrm{~N}\right]$. 


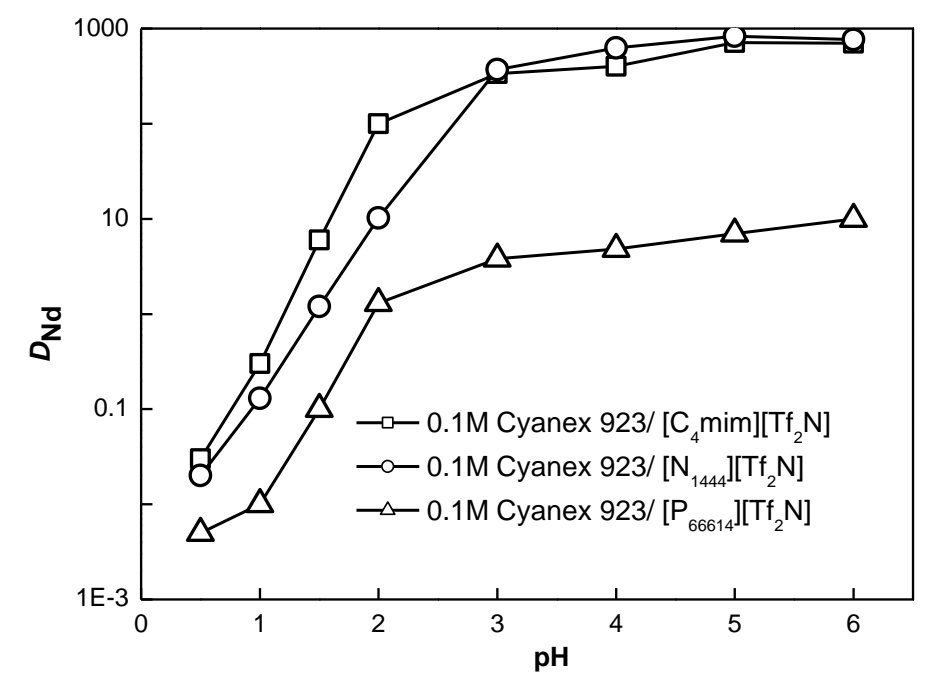

Figure 2. Variation of the distribution ratio of $\mathrm{Nd}(\mathrm{III})$ as a function of the $\mathrm{pH}$ of the aqueous phase.

To exclude that the difference in extraction mechanism is due to the type of cation rather than the length of the alkyl chains (hydrophobic), analogues of $\left[\mathrm{C}_{4} \mathrm{mim}\right]\left[\mathrm{Tf}_{2} \mathrm{~N}\right]$ and $\left[\mathrm{N}_{1444}\right]\left[\mathrm{Tf}_{2} \mathrm{~N}\right]$ with longer alkyl chains were considered as diluents for extraction of $\mathrm{Nd}(\mathrm{III})$ with Cyanex 923: $\left[\mathrm{C}_{10} \mathrm{mim}\right]\left[\mathrm{Tf}_{2} \mathrm{~N}\right]$ and $\left[\mathrm{N}_{1888}\right]\left[\mathrm{Tf}_{2} \mathrm{~N}\right]$. 


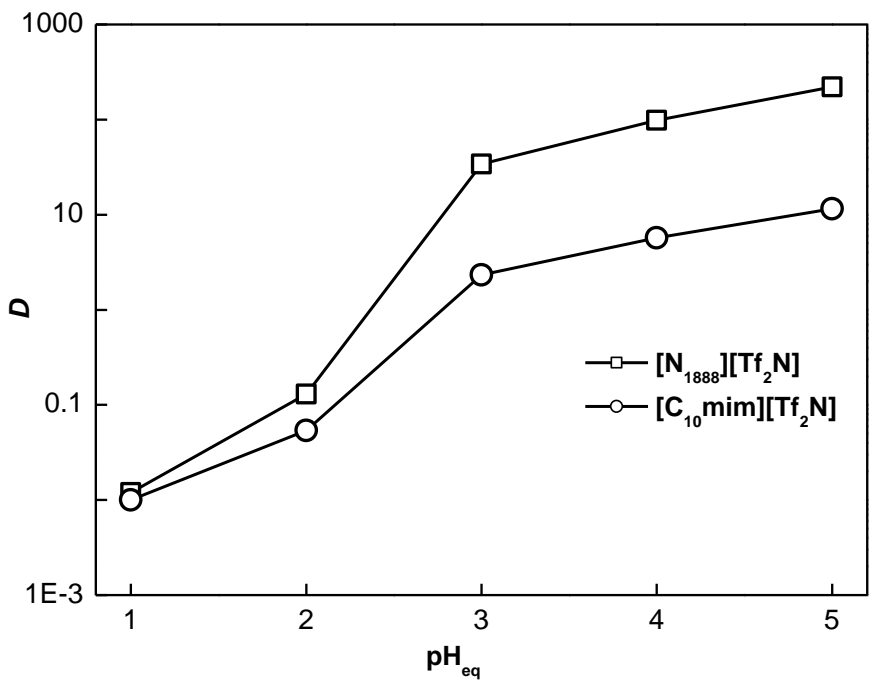

Figure 3. Variation of the distribution ratio of $\mathrm{Nd}(\mathrm{III})$ as a function of the equilibrium $\mathrm{pH}$ of the aqueous phase.

\section{Extraction mechanism}

The two possible mechanisms for extraction of a $\mathrm{Nd}(\mathrm{III})$ ion from the aqueous phase to the ionic liquid phase are the ion exchange mechanism and the neutral mechanism (also called the solvation mechanism) In case of an ion exchange mechanism, the $\mathrm{Nd}^{3+}$ ion or a positively charged $\mathrm{Nd}(\mathrm{III})$ complex are extracted to the ionic liquid phase by cation exchange, while simultaneously ionic liquid cations are transferred to the water phase for the reasons of charge balance. Also solvating Cyanex 923 molecules are involved in the extraction process. The ion exchange mechanism can be represented by the following equations, depending on the type of positively charged $\mathrm{Nd}(\mathrm{III})$ complex that is formed.

$$
\mathrm{Nd}^{3+}+n \bar{L}+3 \overline{Q\left[\mathrm{Tf}_{2} \mathrm{~N}\right]} \leftrightarrows \overline{\mathrm{Nd} L_{n}\left(\mathrm{Tf}_{2} \mathrm{~N}\right)_{3}}+3 Q^{+}
$$




$$
\left[\mathrm{Nd}\left(\mathrm{NO}_{3}\right)\right]^{2+}+n \bar{L}+2 \overline{Q\left[\mathrm{Tf}_{2} \mathrm{~N}\right]} \leftrightarrows \overline{\mathrm{Nd} L_{n}\left(\mathrm{NO}_{3}\right)\left(\mathrm{Tf}_{2} \mathrm{~N}\right)_{2}}+2 Q^{+}
$$

$\left[\mathrm{Nd}\left(\mathrm{NO}_{3}\right)_{2}\right]^{+}+n \bar{L}+\overline{Q\left[\mathrm{Tf}_{2} \mathrm{~N}\right]} \leftrightarrows \overline{\mathrm{Nd} L_{n}\left(\mathrm{NO}_{3}\right)_{2}\left(\mathrm{Tf}_{2} \mathrm{~N}\right)}+Q^{+}$

The bar indicates molecules in the ionic liquid phase. $L$ stands for a Cyanex 923 molecule and $Q^{+}$is the ionic liquid cation. In that the $\mathrm{Nd}\left(\mathrm{NO}_{3}\right)_{3}$ complex is formed, $\mathrm{Nd}(\mathrm{III})$ is extracted as a neutral complex (neutral mechanism):

$\mathrm{Nd}^{3+}+3 \mathrm{NO}_{3}^{-}+n \bar{L} \leftrightarrows \overline{\mathrm{Nd}_{\left(\mathrm{NO}_{3}\right)_{3} L_{n}}}$

Here the bar represents again molecules in the ionic liquid phase and $L$ stands for a Cyanex 923 molecule. The main difference with the ion exchange mechanism shown in equations (5)-(7), is that in the case of a neutral mechanism no ionic liquid cations are transferred to the aqueous phase. The extracted metal complexes can contain a different number of Cyanex 923 molecules. Moreover, there is a possibility that water molecules coordinate to $\mathrm{Nd}(\mathrm{III})$ in order to saturate the coordination sphere. The expected coordination number for this type of complexes is between 8 and 10. To find out what was the extraction mechanism in the ionic liquids at given conditions, different types of extraction experiments have been done.

The number of coordinated Cyanex 923 molecules was determined by variation of the concentration of Cyanex 923 in the ionic liquid phases. The distribution ratio $D$ 
increased with an increase in the concentration of Cyanex 923 in the ionic liquid (Figure 4). A linear regression analysis of $\log D$ versus $\log [$ Cyanex923] of the extraction data gave a straight line with slope values of 2.80 for $\left[\mathrm{C}_{4} \mathrm{mim}\right]\left[\mathrm{Tf}_{2} \mathrm{~N}\right]$ and 3.11 for $\left[\mathrm{N}_{1444}\right]\left[\mathrm{Tf}_{2} \mathrm{~N}\right]$, whereas a slope value of 1.83 was obtained in case of $\left[\mathrm{P}_{66614}\right]\left[\mathrm{Tf}_{2} \mathrm{~N}\right]$. This suggests that three molecules of Cyanex 923 are involved during extraction to the ionic liquids $\left[\mathrm{C}_{4} \mathrm{mim}\right]\left[\mathrm{Tf}_{2} \mathrm{~N}\right]$ and $\left[\mathrm{N}_{1444}\right]\left[\mathrm{Tf}_{2} \mathrm{~N}\right]$ and two molecules are involved in case of the ionic liquid $\left[\mathrm{P}_{66614}\right]\left[\mathrm{Tf}_{2} \mathrm{~N}\right]$.

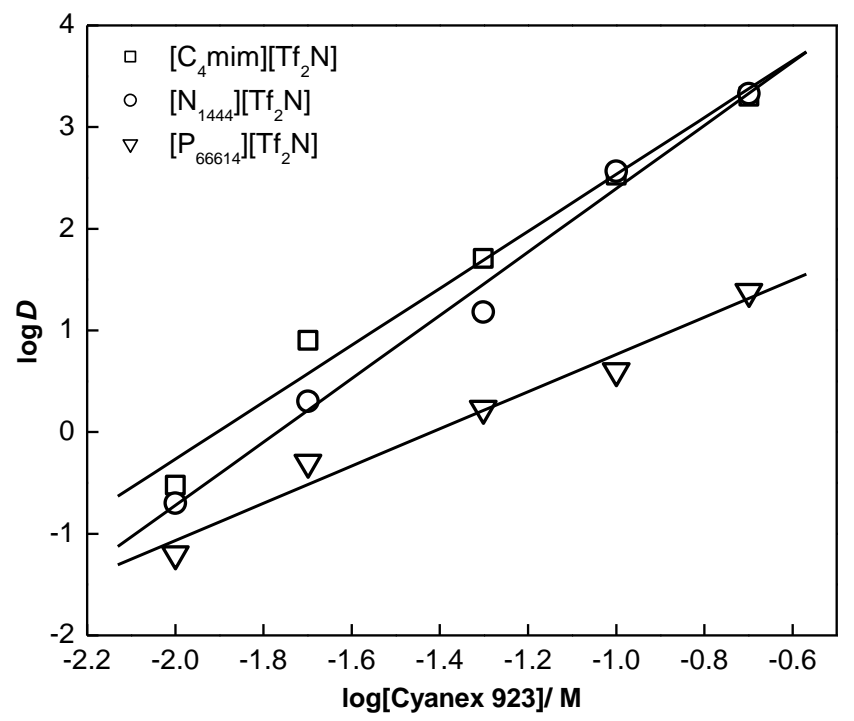

Figure 4. Variation in the plot of $\log D$ as a function of $\log [$ Cyanex 923] for the extraction of $\mathrm{Nd}(\mathrm{III})$.

To find evidence for an ion-exchange mechanism, the extraction of $\mathrm{Nd}(\mathrm{III})$ by 0.1M Cyanex 923 in $\left[\mathrm{C}_{4} \mathrm{mim}\right]\left[\mathrm{Tf}_{2} \mathrm{~N}\right]$ or $\left[\mathrm{N}_{1444}\right]\left[\mathrm{Tf}_{2} \mathrm{~N}\right]$ was carried out from an aqueous phase $(\mathrm{pH} 3)$ containing various concentrations of $\left[\mathrm{C}_{4} \mathrm{mim}\right][\mathrm{Cl}]$ and $\left[\mathrm{N}_{1444}\right][\mathrm{Cl}]$, 
respectively. Chloride rather than nitrate salts were used to avoid simultaneous change in the nitrate ion concentration while the ionic liquid cation concentration was varied. The use of a chloride salt is justified, because chloride ions do not form inner sphere complexes with rare-earth ions at chloride concentrations of lower than $5 \mathrm{M}^{68}$ The distribution ratios decrease gradually with increase in the concentration of the ionic liquid cation in the aqueous phase (Figure 5). These observations are an indication that $\mathrm{Nd}(\mathrm{III})$ gets extracted to the ionic liquid phase at the expense of $\left[\mathrm{C}_{4} \mathrm{mim}\right]^{+}$or $\left[\mathrm{N}_{1444}\right]^{+}$cations, which are transferred to the aqueous phase. This decrease in distribution ratios is due to the common-ion effect in the aqueous phase. The concentration of $\left[\mathrm{N}_{1444}\right]^{+}$cations in the aqueous phase has a larger effect on the distribution ratios than the concentration of $\left[\mathrm{C}_{4} \mathrm{mim}\right]^{+}$cations. A difference between the two cations is that $\left[\mathrm{N}_{1444}\right]^{+}$has a strongly localized positive charge, whereas $\left[\mathrm{C}_{4} \mathrm{mim}\right]^{+}$has a delocalized positive charge. This leads to a stronger cation-anion interaction between cation and anion in the ionic liquid phase for $\left[\mathrm{N}_{1444}\right]^{+}$than for $\left[\mathrm{C}_{4} \mathrm{mim}\right]^{+}$, and thus to a stronger drive for the backward reaction in equation (5). In the case of $\left[\mathrm{C}_{10} \mathrm{mim}\right]\left[\mathrm{Tf}_{2} \mathrm{~N}\right]$ with addition of $\left[\mathrm{C}_{10} \mathrm{mim}\right] \mathrm{Cl}$ to the aqueous, the distribution ratios remained within the experimental errors constant as a function of the $\left[\mathrm{C}_{10} \mathrm{mim}\right]^{+}$aq concentration but the distribution ratios are very small. A similar experiment with $\left[\mathrm{P}_{66614}\right][\mathrm{Cl}]$ was not possible, due to the very low solubility of $\left[\mathrm{P}_{66614}\right][\mathrm{Cl}]$ in the aqueous phase. 


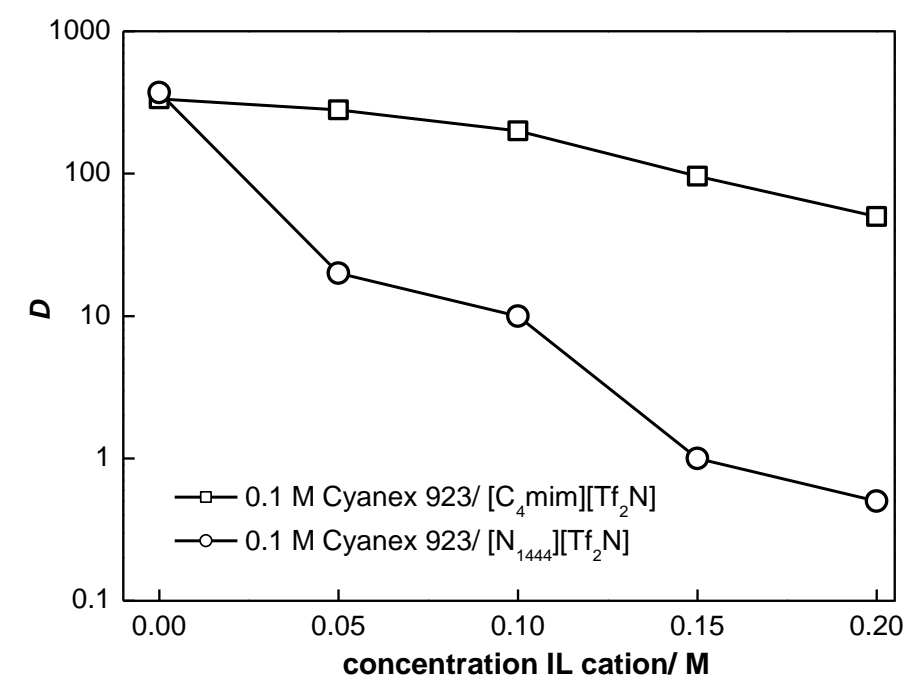

Figure 5. Variation of the distribution ratio $D$ of $\mathrm{Nd}(\mathrm{III})$ as a function of the concentration of $\left[\mathrm{C}_{4} \mathrm{mim}\right][\mathrm{Cl}]$ or $\left[\mathrm{N}_{1444}\right][\mathrm{Cl}]$ concentration in the aqueous phase.

Experiments were carried out under similar experimental conditions $(0.1 \mathrm{M}$ Cyanex923 dissolved in the ionic liquid), but with varying nitrate concentrations in the aqueous phase at $\mathrm{pH} 3$ (Figure 6). The distribution ratios remain almost constant as a function of the nitrate concentration in the case of $\left[\mathrm{C}_{4} \mathrm{mim}\right]\left[\mathrm{Tf}_{2} \mathrm{~N}\right]$ and $\left[\mathrm{N}_{1444}\right]\left[\mathrm{Tf}_{2} \mathrm{~N}\right]$. This suggests that nitrate ions are not involved in the extraction mechanism and that these ionic liquids do not promote the uptake of $\mathrm{Nd}\left(\mathrm{NO}_{3}\right)_{3},\left[\mathrm{Nd}\left(\mathrm{NO}_{3}\right)_{2}\right]^{+}$or $\left[\mathrm{Nd}\left(\mathrm{NO}_{3}\right)\right]^{2+}$; but that $\mathrm{Nd}^{3+}$ is extracted by the cation exchange mechanism shown in equation (5). On the other hand, the distribution ratios increase sharply with an increase in the nitrate concentration in the aqueous phase in the case of $0.1 \mathrm{M}$ Cyanex 923 in $\left[\mathrm{P}_{66614}\right]\left[\mathrm{Tf}_{2} \mathrm{~N}\right]$. This indicates that the metal ion is extracted in the form of a $\mathrm{Nd}(\mathrm{III})$ nitrate complex, as represented by equations (6), (7) or (8). For $\left[\mathrm{N}_{1888}\right]\left[\mathrm{Tf}_{2} \mathrm{~N}\right]$ and $\left[\mathrm{C}_{10} \operatorname{mim}\right]\left[\mathrm{Tf}_{2} \mathrm{~N}\right]$, the $D$ 
values also increase with increase in nitrate ion concentration and show that nitrate ions are involved in the extraction process (Figure 7). The cation in $\left[\mathrm{N}_{1888}\right]\left[\mathrm{Tf}_{2} \mathrm{~N}\right]$ is a major component of Aliquat 336, which has been used in its chloride or nitrate form for solvent extraction studies. ${ }^{21,23,69}$ Since the $\left[\mathrm{N}_{1888}\right]^{+}$cation is more hydrophobic than the $\left[\mathrm{N}_{1444}\right]^{+}$ cation, the ion-exchange mechanism is suppressed, similarly to what was observed for $\left[\mathrm{P}_{66614}\right]\left[\mathrm{Tf}_{2} \mathrm{~N}\right]$. The low $D$ values for the ionic liquids $\left[\mathrm{C}_{10} \operatorname{mim}\right]\left[\mathrm{Tf}_{2} \mathrm{~N}\right],\left[\mathrm{N}_{1888}\right]\left[\mathrm{Tf}_{2} \mathrm{~N}\right]$ and $\left[\mathrm{P}_{66614}\right]\left[\mathrm{Tf}_{2} \mathrm{~N}\right]$ in the absence of extra added nitrate ions in the aqueous solutions, indicate that these ionic liquids also extract via an ion exchange mechanism under these circumstances and that the low $D$ values are due to the limited solubility of the ionic liquid cation in the aqueous phase. This also explains why the $\mathrm{D}$ values are smaller for $\left[\mathrm{P}_{66614}\right]\left[\mathrm{Tf}_{2} \mathrm{~N}\right]$ than for $\left[\mathrm{N}_{1888}\right]\left[\mathrm{Tf}_{2} \mathrm{~N}\right]$ : the $\left[\mathrm{P}_{66614}\right]^{+}$cation has a lower solubility in the aqueous phase than the $\left[\mathrm{N}_{1888}\right]^{+}{ }^{23}$ The increase in $\mathrm{D}$ values upon addition of nitrate ions are an indication for a gradual shift from an ion exchange to a neutral mechanism, i.e. extraction via the mechanism shown in equations (5), (6), (7) to finally extraction via the mechanism shown in equation (8). 


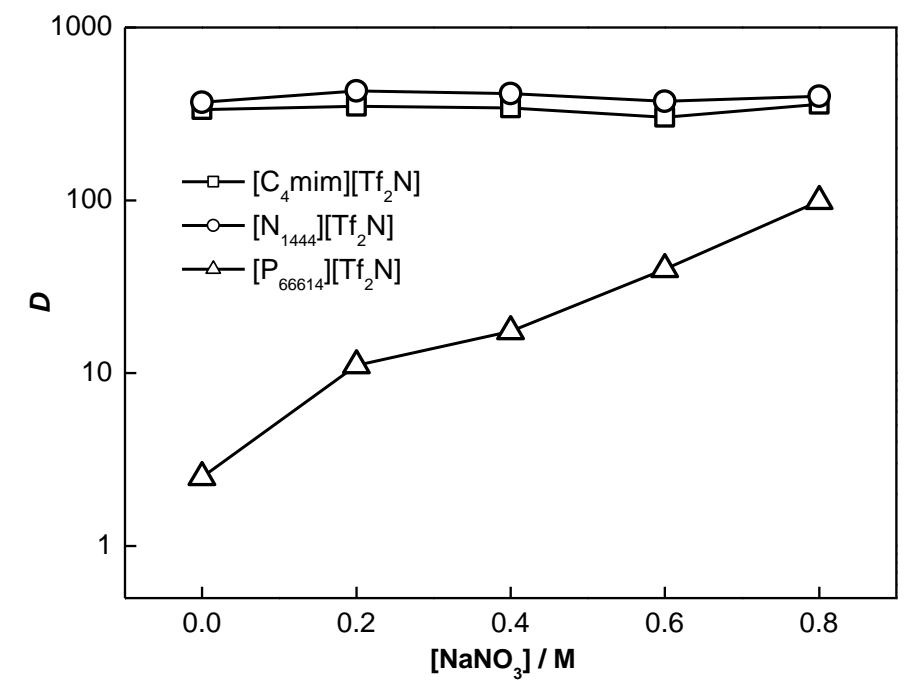

Figure 6. Variation of the distribution ratio of $\mathrm{Nd}(\mathrm{III})$ for extraction with Cyanex 923 as a function of the nitrate concentration in the aqueous phase.

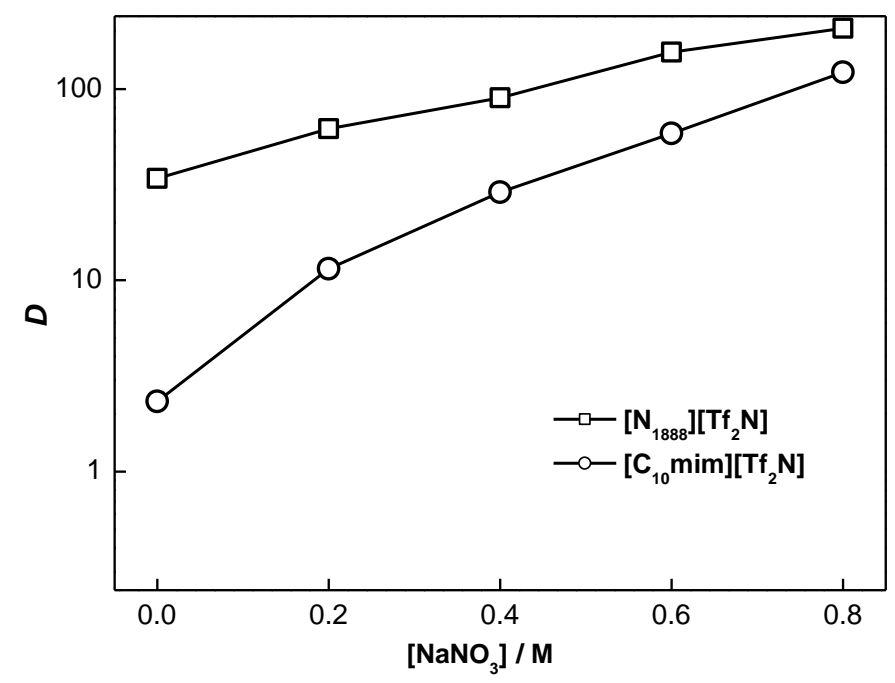

Figure 7. Variation of the distribution ratio of $\mathrm{Nd}(\mathrm{III})$ for extraction with Cyanex 923 a function of nitrate concentration in the aqueous phase. 
To probe the local environment of the rare-earth ion, luminescence spectra of $\mathrm{Eu}(\mathrm{III})$ in the aqueous phase and of the extracted $\mathrm{Eu}(\mathrm{III})$ complexes in the ionic liquid phases were recorded (Figure 8). Eu(III) was selected instead of $\mathrm{Nd}(\mathrm{III})$, because $\mathrm{Eu}(\mathrm{III})$ is a well-known spectroscopic probe and emits in the visible range (red spectral region). $\mathrm{Nd}(\mathrm{III})$ is an near-infrared emitter and $\mathrm{Nd}(\mathrm{III})$ luminescence is totally quenched by coordinated water molecules. The splitting pattern, shape and relative intensities of the ${ }^{5} \mathrm{D}_{0} \rightarrow{ }^{7} \mathrm{~F}_{J}$ emission bands can provide information on the chemical environment of the $\mathrm{Eu}(\mathrm{III})$ ion. The transitions in the luminescence spectrum originate from the ${ }^{5} \mathrm{D}_{0}$ level and terminate at the various ${ }^{7} \mathrm{~F}_{J}$ levels ( $J$ from 0 to 6 ; only $J=0-4$ observed in the operational wavelength range of the detector). The hypersensitive transition ${ }^{5} \mathrm{D}_{0} \rightarrow{ }^{7} \mathrm{~F}_{2}$ is the most intense transition in the spectrum of the ionic liquid phases, but the magnetic dipole transition ${ }^{5} \mathrm{D}_{0} \rightarrow{ }^{7} \mathrm{~F}_{1}$ is the most intense transition in the luminescence spectrum of the aqueous phase. These results show that the local environment of the $\mathrm{Eu}(\mathrm{III})$ ion is different in the ionic liquid phases compared to the aqueous phase due to the complex formation of $\mathrm{Eu}(\mathrm{III})$ in the ionic liquid phase. The relative intensities of the different transitions of the $\mathrm{Eu}(\mathrm{III})$ spectra in the three ionic liquids $\left[\mathrm{C}_{4} \mathrm{mim}\right]\left[\mathrm{Tf} \mathrm{f}_{2} \mathrm{~N}\right],\left[\mathrm{N}_{1444}\right]\left[\mathrm{Tf}_{2} \mathrm{~N}\right]$ and $\left[\mathrm{P}_{66614}\right]\left[\mathrm{Tf} f_{2} \mathrm{~N}\right]$ are very comparable. Also the fine structure is quite similar, although some small differences are observed for $\left[\mathrm{C}_{4} \mathrm{mim}\right]\left[\mathrm{Tf}_{2} \mathrm{~N}\right]$ compared to the other two ionic liquids. This indicates similarities in the structure of the extracted complexes. This is an indication for similar extraction mechanisms, as indicated by equation (5). It also suggests that although three molecules of Cyanex 923 are involved in the extraction process in the ionic liquid $\left[\mathrm{N}_{1444}\right]\left[\mathrm{Tf}_{2} \mathrm{~N}\right]$ only two of these molecules are in the first 
coordination sphere of $\mathrm{Eu}(\mathrm{III})$. The number of water molecules present in the innersphere (first coordination sphere) of the Eu(III) complex in different ionic liquids was determined by measuring the decay time of the ${ }^{5} \mathrm{D}_{0}$ emitting level (via monitoring the emission intensity of the hypersensitive transition ${ }^{5} \mathrm{D}_{0} \rightarrow{ }^{7} \mathrm{~F}_{2}$ at $615 \mathrm{~nm}$ under excitation at $464 \mathrm{~nm}$ ) and by applying the Horrocks-Sudnick equation: ${ }^{70}$

$$
q=1.05\left(\frac{1}{\tau_{\mathrm{H}_{2} \mathrm{O}}}-\frac{1}{\tau_{\mathrm{D}_{2} \mathrm{O}}}\right)
$$

Here $q$ is the number of water molecules in the first coordination sphere (inner-sphere) of the $\mathrm{Eu}^{3+}$ ion. $\boldsymbol{\tau}_{\mathbf{H}_{\mathbf{2}} \mathbf{O}}$ and $\boldsymbol{\tau}_{\mathbf{D}_{\mathbf{2}} \mathbf{0}}$ are the luminescence decay times measured in water and heavy water, respectively. The average life times were $1.63 \mathrm{~ms}$ in $\mathrm{D}_{2} \mathrm{O}$ versus $0.56 \mathrm{~ms}$ in $\mathrm{H}_{2} \mathrm{O}$ for $\left[\mathrm{C}_{4} \mathrm{mim}\right]\left[\mathrm{Tf}_{2} \mathrm{~N}\right], 1.91 \mathrm{~ms}$ in $\mathrm{D}_{2} \mathrm{O}$ versus $1.52 \mathrm{~ms}$ in $\mathrm{H}_{2} \mathrm{O}$ for $\left[\mathrm{N}_{1444}\right]\left[\mathrm{Tf}_{2} \mathrm{~N}\right]$ and $1.92 \mathrm{~ms}$ in $\mathrm{D}_{2} \mathrm{O}$ versus $1.77 \mathrm{~ms}$ in $\mathrm{H}_{2} \mathrm{O}$ for $\left[\mathrm{P}_{66614}\right]\left[\mathrm{Tf}_{2} \mathrm{~N}\right]$, respectively. After filling in these values in equation (9), a $q$ value of 1.2 is obtained for $\left[\mathrm{C}_{4} \operatorname{mim}\right]\left[\mathrm{Tf}_{2} \mathrm{~N}\right]$, a value of 0.14 for $\left[\mathrm{N}_{1444}\right]\left[\mathrm{Tf}_{2} \mathrm{~N}\right]$ and a value of 0.04 for $\left[\mathrm{P}_{66614}\right]\left[\mathrm{Tf}_{2} \mathrm{~N}\right]$. These values indicate that there is no water molecule present in the inner coordination sphere of the $\mathrm{Eu}(\mathrm{III})$ complexes in $\left[\mathrm{N}_{1444}\right]\left[\mathrm{Tf}_{2} \mathrm{~N}\right]$ or $\left[\mathrm{P}_{66614}\right]\left[\mathrm{Tf}_{2} \mathrm{~N}\right]$ and that one molecule of water is present in $\left[\mathrm{C}_{4} \mathrm{mim}\right]\left[\mathrm{Tf}_{2} \mathrm{~N}\right]$. It should be noticed that we have used the Horrocks-Sudnick formula and not the modified Supkowski-Horrocks formula because the latter gave negative $q$ values. ${ }^{71,72}$ This is due to the fact that the Supkowski-Horrocks formula should be used only in aqueous solutions and not in hydrated ionic liquids, since the modified formula takes in account water molecules in the second coordination sphere of the Eu(III) ion and the water concentration is lower in hydrated ionic liquids than in bulk water. ${ }^{73}$ 


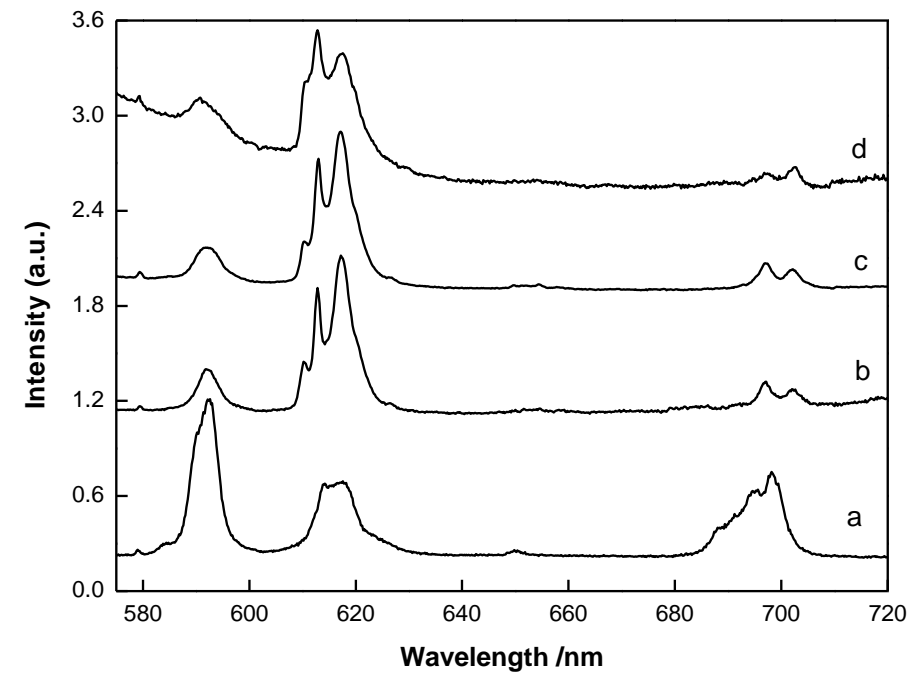

Figure 8. Emission spectra of $\mathrm{Eu}(\mathrm{III})$ in the aqueous feed solution and of $\mathrm{Eu}(\mathrm{III})$ complexes extracted by Cyanex 923 to ionic liquid phases. $\left(\lambda_{\text {exc }}=395 \mathrm{~nm}\right.$, room temperature): (a) aqueous feed solution; (b) $\left[\mathrm{P}_{66614}\right]\left[\mathrm{Tf}_{2} \mathrm{~N}\right]$; (c) $\left[\mathrm{N}_{1444}\right]\left[\mathrm{Tf}_{2} \mathrm{~N}\right]$; (d) $\left[\mathrm{C}_{4} \operatorname{mim}\right]\left[\mathrm{Tf}_{2} \mathrm{~N}\right]$.

\section{Loading of ionic liquid phase}

The effect of metal concentration in the feed was investigated by using $0.1 \mathrm{M}$ Cyanex 923 dissolved in all the $\left[\mathrm{C}_{4} \mathrm{mim}\right]\left[\mathrm{Tf}_{2} \mathrm{~N}\right],\left[\mathrm{N}_{1444}\right]\left[\mathrm{Tf}_{2} \mathrm{~N}\right]$ and $\left[\mathrm{P}_{66614}\right]\left[\mathrm{Tf}_{2} \mathrm{~N}\right]$ (Figure 9). It was observed that the ionic liquid phase loading was in the order of $\left[\mathrm{C}_{4} \mathrm{mim}\right]\left[\mathrm{Tf}_{2} \mathrm{~N}\right]$ $>\left[\mathrm{N}_{1444}\right]\left[\mathrm{Tf}_{2} \mathrm{~N}\right]>\left[\mathrm{P}_{66614}\right]\left[\mathrm{Tf}_{2} \mathrm{~N}\right]: 16 \mathrm{mmol} \mathrm{L}^{-1} \mathrm{Nd}(\mathrm{III})$ could be loaded in $\left[\mathrm{C}_{4} \mathrm{mim}\right]\left[\mathrm{Tf}_{2} \mathrm{~N}\right], 12 \mathrm{mmol} \mathrm{L}^{-1}$ in $\left[\mathrm{N}_{1444}\right]\left[\mathrm{Tf}_{2} \mathrm{~N}\right]$ and $5 \mathrm{mmol} \mathrm{L}^{-1}$ in $\left[\mathrm{P}_{66614}\right]\left[\mathrm{Tf}_{2} \mathrm{~N}\right]$. The highest loadings are thus observed for ionic liquids with hydrophilic cations. However, the loading in the ionic liquid $\left[\mathrm{P}_{66614}\right]\left[\mathrm{Tf}_{2} \mathrm{~N}\right]$ could be increases by increasing the nitrate 
concentration in the aqueous phase, as shown by adding $0.8 \mathrm{M} \mathrm{NO}_{3}{ }^{-}$to the aqueous phase: the loading increased from $5 \mathrm{mmol} \mathrm{L}^{-1}$ to $17 \mathrm{mmol} \mathrm{L}^{-1}$ (Figure 10)

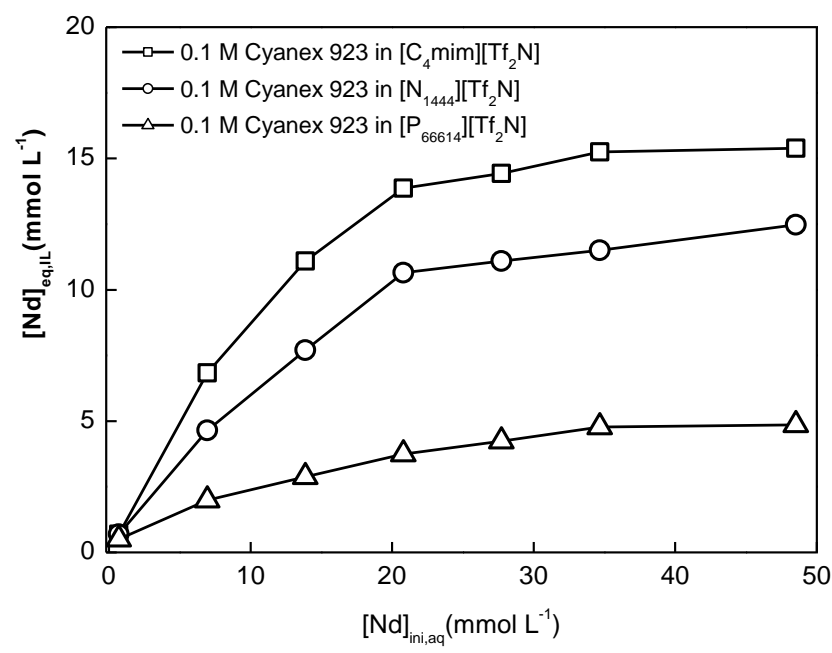

Figure 9. Variation of $[\mathrm{Nd}]_{\mathrm{eq}, \mathrm{IL}}$ as a function of $[\mathrm{Nd}]_{\text {ini,aq. }}$ Aqueous phase: $\mathrm{pH} 3$.

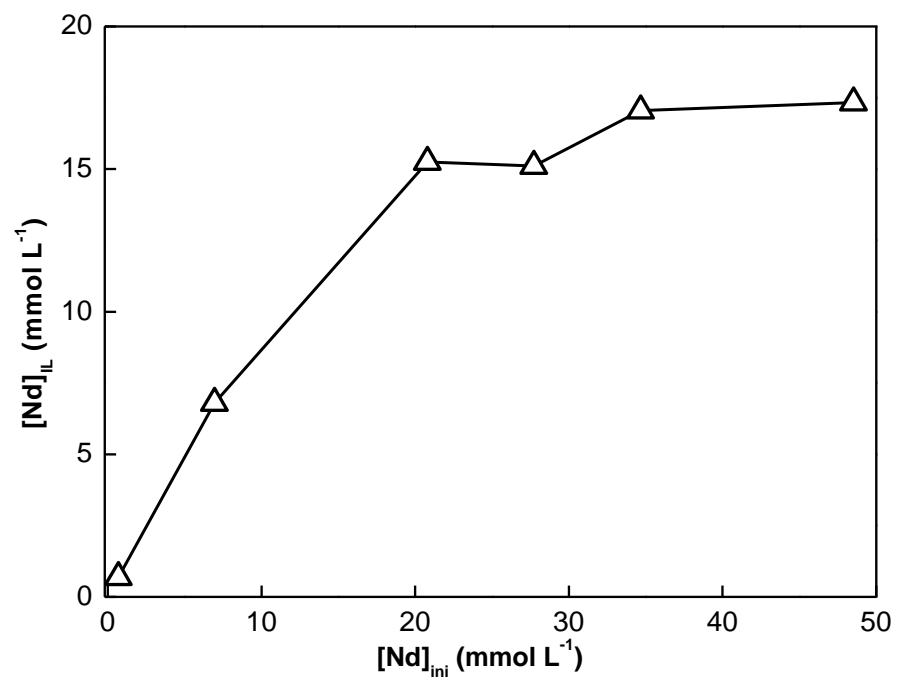

Figure 10. Variation of $[\mathrm{Nd}]_{\mathrm{eq}, \mathrm{IL}}$ as a function of $[\mathrm{Nd}]_{\mathrm{ini}, \mathrm{aq}}$ for extraction with Cyanex 923 in $\left[\mathrm{P}_{66614}\right]\left[\mathrm{Tf}_{2} \mathrm{~N}\right]$. Aqueous phase: $\mathrm{pH} 3+0.8 \mathrm{M} \mathrm{NO}_{3}{ }^{-}$(as $\left.\mathrm{NaNO}_{3}\right)$. 


\section{Extraction of different rare-earth ions}

The performance of Cyanex 923 for extraction of different rare-earth ions was investigated in the ionic liquids $\left[\mathrm{C}_{4} \mathrm{mim}\right]\left[\mathrm{Tf}_{2} \mathrm{~N}\right],\left[\mathrm{N}_{1444}\right]\left[\mathrm{Tf}_{2} \mathrm{~N}\right]$ and $\left[\mathrm{P}_{66614}\right]\left[\mathrm{Tf}_{2} \mathrm{~N}\right]$, using a mixture of different rare-earth nitrate salts in one aqueous feed solution (Figure 11). As it can be noticed, the distribution ratios of all the rare earths increase across the lanthanide series and the extracting capacity of Cyanex 923 with respect to the type of ionic liquid follows the order $\left[\mathrm{C}_{4} \mathrm{mim}\right]\left[\mathrm{Tf}_{2} \mathrm{~N}\right]>\left[\mathrm{N}_{1444}\right]\left[\mathrm{Tf}_{2} \mathrm{~N}\right]>\left[\mathrm{P}_{66614}\right]\left[\mathrm{Tf}_{2} \mathrm{~N}\right]$. This order reflects the solubility of the ionic liquid cation in the aqueous phase. It was observed that the distribution ratios decreased when $\mathrm{Nd}(\mathrm{III})$ was mixed with other rare-earth ions, compared to extraction of $\mathrm{Nd}(\mathrm{III})$ from a solution in which only $\mathrm{Nd}(\mathrm{III})$ was present. This is due to competition of all the different metal ions for complex formation with the extractant. From the distribution ratios, the separation factors were calculated using equation (4). In Table 1, the separation factors for pairs of different rare-earth ions are shown. The separation factors depend on the type of ionic liquids. The separation factors for Cyanex 923 in $\left[\mathrm{C}_{4} \mathrm{mim}\right]\left[\mathrm{Tf}_{2} \mathrm{~N}\right]$ are smaller than those for the other ionic liquids. From Table 1 and Figure 11, it is evident that $\mathrm{La}(\mathrm{III})$ and to a lesser extent $\mathrm{Ce}(\mathrm{III})$ and $\mathrm{Pr}(\mathrm{III})$ are much less efficiently extracted than the other lanthanide ions. This suggests that these ionic liquids can be used to separate these elements from the heavier lanthanides.

However, the separations factors between neighboring lanthanide ions are too small to be of practical use for separation of mixtures of heavy lanthanides. The position of Y(III) is between $\mathrm{Ho}(\mathrm{III})$ and $\mathrm{Yb}(\mathrm{III})$, irrespective of the type of ionic liquid. 


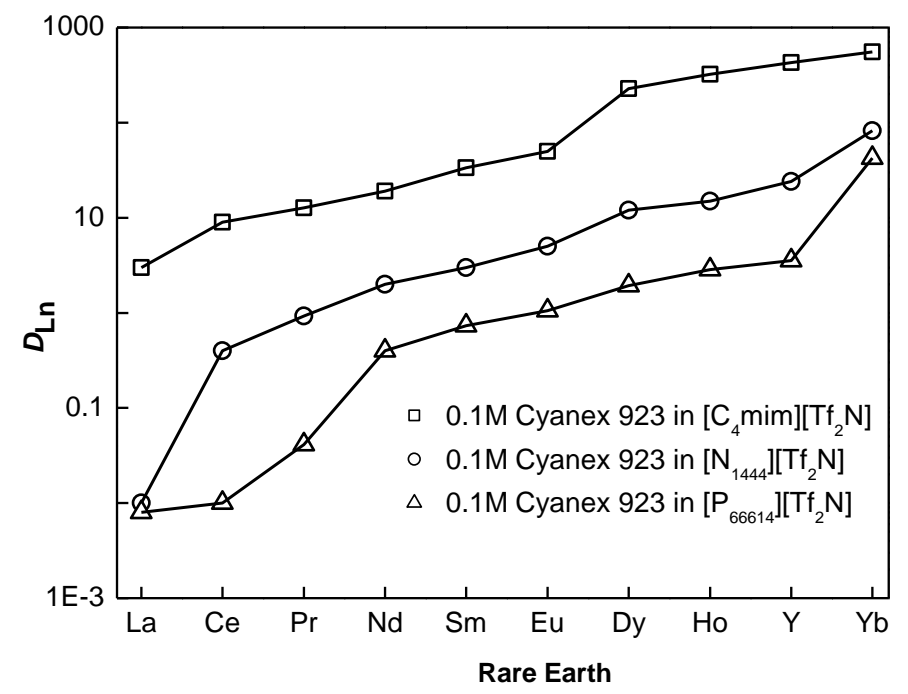

Figure 11. Variation of the distribution ratios as a function of the rare-earth ion. Aqueous phase: $\mathrm{pH} 3$ and rare-earth ion $\operatorname{Ln}(\mathrm{IIII})\left(7 \times 10^{-4} \mathrm{M}\right.$ each). 
Table 1. Separation factors $(\beta)$ of rare-earth ions of a mixture of different metal ions at a concentration of $7 \times 10^{-4} \mathrm{M}$ each.

\begin{tabular}{|c|c|c|c|c|c|c|c|c|c|}
\hline \multicolumn{10}{|c|}{0.1 M Cyanex 923 in $\left[\mathrm{C}_{4} \operatorname{mim}\right]\left[\mathrm{Tf}_{2} \mathrm{~N}\right]$} \\
\hline & $\mathrm{Ce}$ & $\operatorname{Pr}$ & $\mathrm{Nd}$ & $\mathrm{Sm}$ & $\mathrm{Eu}$ & Dy & Ho & $\mathrm{Y}$ & $\mathrm{Yb}$ \\
\hline $\mathrm{La}$ & 3 & 4.2 & 6.3 & 11 & 1.6 & 76 & 107 & 142 & 185 \\
\hline $\mathrm{Ce}$ & & 1.4 & 2 & 4 & 5.5 & 25 & 36 & 47 & 62 \\
\hline $\operatorname{Pr}$ & & & 1.5 & 3.0 & 4.0 & 18 & 25 & 34 & 44 \\
\hline $\mathrm{Nd}$ & & & & 1.8 & 2.6 & 12 & 17 & 22 & 29 \\
\hline $\mathrm{Sm}$ & & & & & 1.5 & 7.0 & 10 & 12.7 & 17 \\
\hline $\mathrm{Eu}$ & & & & & & 4.5 & 6.4 & 8.5 & 11 \\
\hline Dy & & & & & & & 1.4 & 1.8 & 2.4 \\
\hline Ho & & & & & & & & 1.3 & 1.7 \\
\hline $\mathrm{Y}$ & & & & & & & & & 1.3 \\
\hline \multicolumn{10}{|c|}{0.1 M Cyanex 923 in $\left[\mathrm{N}_{1444}\right]\left[\mathrm{Tf}_{2} \mathrm{~N}\right]$} \\
\hline $\mathrm{La}$ & 40 & 92 & 200 & 300 & 500 & 1200 & 1500 & 2400 & 8200 \\
\hline $\mathrm{Ce}$ & & 2.3 & 5 & 7.5 & 12.5 & 30 & 38 & 60 & 206 \\
\hline $\operatorname{Pr}$ & & & 2.2 & 3.2 & 4.0 & 13 & 16 & 26 & 89 \\
\hline $\mathrm{Nd}$ & & & & 1.5 & 2.5 & 6.0 & 7.5 & 12 & 41 \\
\hline $\mathrm{Sm}$ & & & & & 1.5 & 6.7 & 9.6 & 12.7 & 16.6 \\
\hline $\mathrm{Eu}$ & & & & & & 4.5 & 6.4 & 8.5 & 11 \\
\hline Dy & & & & & & & 1.4 & 1.8 & 2.4 \\
\hline Ho & & & & & & & & 1.3 & 1.7 \\
\hline $\mathrm{Y}$ & & & & & & & & & 3.0 \\
\hline \multicolumn{10}{|c|}{$0.1 \mathrm{M}$ Cyanex 923 in $\left[\mathrm{P}_{66614}\right]\left[\mathrm{Tf}_{2} \mathrm{~N}\right]$} \\
\hline $\mathrm{La}$ & 1.2 & 5 & 50 & 91 & 131 & 241 & 355 & 443 & 5200 \\
\hline $\mathrm{Ce}$ & & 4 & 40 & 73 & 105 & 193 & 284 & 355 & 4200 \\
\hline $\operatorname{Pr}$ & & & 10 & 18 & 26 & 47 & 70 & 86 & 1000 \\
\hline $\mathrm{Nd}$ & & & & 1.8 & 2.6 & 5.0 & 7.0 & 9.0 & 105 \\
\hline $\mathrm{Sm}$ & & & & & 1.4 & 2.6 & 4.0 & 5.0 & 58 \\
\hline $\mathrm{Eu}$ & & & & & & 1.8 & 2.7 & 3.4 & 40 \\
\hline Dy & & & & & & & 1.4 & 2.0 & 22 \\
\hline Нo & & & & & & & & 1.2 & 15 \\
\hline Y & & & & & & & & & 12 \\
\hline
\end{tabular}




\section{Stripping studies}

Since the combination of Cyanex 923 with the different ionic liquid diluents is able to extract $\mathrm{Nd}(\mathrm{III})$ even from solutions with a low $\mathrm{pH}$ value, it is likely that all the loaded metal ions have to be stripped from the ionic liquid phase by strongly acidic solutions. It was observed that $60 \%$ and $65 \%$ of $\mathrm{Nd}(\mathrm{III})$ was stripped back from $\left[\mathrm{C}_{4} \mathrm{mim}\right]\left[\mathrm{Tf}_{2} \mathrm{~N}\right]$ and $\left[\mathrm{N}_{1444}\right]\left[\mathrm{Tf}_{2} \mathrm{~N}\right]$ phase with a $0.5 \mathrm{M} \mathrm{HNO}_{3}$ solution. It was observed that the stripping percentage increased gradually by increasing the acidity of the stripping phase and $100 \%$ of metal ion could be stripped back by using $1 \mathrm{M}$ nitric acid (Table 2). On the contrary, due to the lower loading of the $\left[\mathrm{P}_{66614}\right]\left[\mathrm{Tf}_{2} \mathrm{~N}\right]$ phase (lower $D$ value), complete stripping of $\mathrm{Nd}$ (III) from this ionic liquid was possible with $0.7 \mathrm{M} \mathrm{HNO}_{3}$. The mechanism of the stripping reaction is exchange of $\mathrm{Nd}^{3+}$ ions by $\mathrm{H}^{+}$ions in the ionic liquid phase. As mentioned earlier in the text, neutral extractants are able to extract acids. By working at high acid concentrations, the extraction of acids is favored over the extraction of metal ions and the extracted metal ions are released from the ionic liquid phase to the aqueous phase. However, $\mathrm{HTf}_{2} \mathrm{~N}$ formed in the ionic liquid phase during stripping of $\mathrm{Nd}^{3+}$ from the aqueous phase will be, at least partially, lost to the aqueous phase due to the high solubility of $\mathrm{HTf}_{2} \mathrm{~N}$ in water. This indicates that ionic liquid cations are lost to the aqueous phase to the extraction step and ionic liquid anions are lost to the aqueous phase during the stripping step. However, if the ionic liquid cations that are lost during the extraction step were recovered (for instance by reverse osmosis), they could be be added as a solution with nitrate counter ions to the stripping solution and the ionic liquid cations would recombine with the $\mathrm{Tf}_{2} \mathrm{~N}^{-}$anions in the aqueous phase to form new ionic liquid molecules that phase-separate of the aqueous phase and dissolve in the ionic liquid phase. 
In this way it is possible to recover the ionic liquid molecules lost to the aqueuous phases. It should be noticed that the losses of $\mathrm{Tf}_{2} \mathrm{~N}^{-}$anions to the aqueous phase occur only if the extraction was done via an ion exchange mechanism. In the case of extraction via a neutral mechanism, $\mathrm{Ln}\left(\mathrm{NO}_{3}\right)_{3}$ will be transferred from the ionic liquid to the aqueous phase upon stripping and no $\mathrm{Tf}_{2} \mathrm{~N}^{-}$anions are lost to the aqueous phase.

Table 2: Stripping percentage of $\mathrm{Nd}(\mathrm{III})$ from the ionic liquid phase with different concentrations of $\mathrm{HNO}_{3}$.

\begin{tabular}{llll}
\hline$\left[\mathrm{HNO}_{3}\right] / \mathrm{M}$ & \multicolumn{2}{l}{ Stripping percentage $(\% S)$} & \\
\cline { 2 - 4 } & {$\left[\mathrm{N}_{1444}\right]\left[\mathrm{Tf}_{2} \mathrm{~N}\right]$} & {$\left[\mathrm{C}_{4} \mathrm{mim}\right]\left[\mathrm{Tf}_{2} \mathrm{~N}\right]$} & {$\left[\mathrm{P}_{66614}\right]\left[\mathrm{Tf}_{2} \mathrm{~N}\right]$} \\
\hline 0.5 & 65 & 62 & 85 \\
0.7 & 67 & 99 & 97 \\
0.8 & 82 & 85 & --- \\
1.0 & 100 & 98 & 99.8 \\
\hline
\end{tabular}

\section{CONCLUSIONS}

This systematic experimental study of the extraction of $\mathrm{Nd}(\mathrm{III})$ by the neutral extractant Cyanex 923 in five different ionic liquids with the bis(trifluoromethylsulfonyl)imide anion shows that the extraction efficiency depends on the type of ionic liquid cation. Ionic liquids with a small hydrophilic cation, such as $\left[\mathrm{C}_{4} \mathrm{mim}\right]\left[\mathrm{Tf}_{2} \mathrm{~N}\right]$ and $\left[\mathrm{N}_{1444}\right]\left[\mathrm{Tf}_{2} \mathrm{~N}\right]$, extract $\mathrm{Nd}(\mathrm{III})$ efficiently via an ion-exchange mechanism from an aqueous nitrate 
solution with transfer of ionic liquid cations to the aqueous phase. Ionic liquids with a hydrophobic cation, such as $\left[\mathrm{P}_{66614}\right]\left[\mathrm{Tf}_{2} \mathrm{~N}\right],\left[\mathrm{C}_{10} \operatorname{mim}\right]\left[\mathrm{Tf}_{2} \mathrm{~N}\right]$ or $\left[\mathrm{N}_{1888}\right]\left[\mathrm{Tf}_{2} \mathrm{~N}\right]$, extract $\mathrm{Nd}(\mathrm{III})$ much less efficiently because the ion-exchange is suppressed by the low solubility of the ionic liquid cation in the ionic liquid phase. The extraction efficiency by these ionic liquids increases by addition of nitrate ions to the aqueous phase. At high nitrate concentrations, neutral neodymium(III) complexes are extracted to the ionic liquid phase, without losses of the ionic liquid components to the aqueous phase. These findings are of importance for the development of solvent extraction processes for the separation of rare earths. For solvent extraction on an industrial scale with a neutral extractant in an ionic liquid diluent, a cation-exchange mechanism with loss of ionic liquid components to the aqueous phase has to be avoided because recovery of the ionic liquid cations from the aqueous waste streams adds costs. The ionic liquid diluent has to be chosen so that the rare-earth ions can be extracted via a neutral mechanism at high nitrate concentrations. Extraction studies on rare-earth ions other than $\mathrm{Nd}(\mathrm{III})$ show that the Cyanex 923 system in the bis(trifluoromethylsulfonyl)imide ionic liquids show potential for the separation of the lightest lanthanides $\mathrm{La}(\mathrm{III}), \mathrm{Ce}(\mathrm{III})$ and $\mathrm{Pr}(\mathrm{III})$ from the heavier one; however, the separation factors are too small for separation of mixtures of heavy lanthanides. The stripping of the rare-earth ions from the loaded ionic liquid phase has been investigated. The mechanism of the stripping reaction is exchange of rare-earth ions by protons in the ionic liquid phase. The $\operatorname{HTf}_{2} \mathrm{~N}$ that is formed in the ionic liquid during the stripping step can be lost to the aqueous phase due to the high solubility of the acid $\mathrm{HTf}_{2} \mathrm{~N}$ in water. Losses of $\mathrm{Tf}_{2} \mathrm{~N}^{-}$anions to the aqueous phase occur only if the extraction was done via an ion exchange mechanism. In the case of extraction via a neutral 
mechanism, $\mathrm{Ln}\left(\mathrm{NO}_{3}\right)_{3}$ will be transferred from the ionic liquid to the aqueous phase upon stripping and no $\mathrm{Tf}_{2} \mathrm{~N}^{-}$anions are lost to the aqueous phase.

\section{Acknowledgments}

This project has been supported by KU Leuven (projects GOA/13/008 and IOF-KP

$\mathrm{RARE}^{3}$ ) and the FWO-Flanders (Pegasus Marie Curie Fellowship to AR). Support by

IoLiTec (Heilbronn, Germany) is also gratefully acknowledged. The emission spectra and

life time measurement studies were carried out with the help of Dr. Ernesto Rezende

Souza. 


\section{Reference list}

1 S. Dai, Y. H. Ju and C. E. Barnes, J. Chem. Soc. Dalton Trans., 1999, 1201-1202.

2 X. Q. Sun, H. M. Luo and S. Dai, Chem. Rev., 2012, 112, 2100-2128.

3 P. R. Vasudeva Rao, K. A. Venkatesan, A. Rout, T. G. Srinivasan and K. Nagarajan, Sep. Sci. Technol., 2012, 47, 204-222.

4 I. Billard, Chapter 256 - Ionic Liquids: New Hopes for Efficient Lanthanide/Actinide Extraction and Separation? In Handbook on the Physics and Chemistry of Rare Earths, ed. J.-C. G. Bünzli and V. K. Pecharsky, Elsevier, 2013, pp 213-273.

5 J. G. Huddleston, H. D. Willauer, R. P. Swatloski, A. E. Visser and R. D. Rogers, Chem. Commun., 1998, 1765-1766.

6 Z. Kolarik, Solvent Extr. Ion Exch., 2013, 31, 24-60.

7 Y. H. Liu, J. Chen and D. Q. Li, Sep. Sci. Technol., 2012, 47, 223-232.

8 N. V. Plechkova and K. R. Seddon, Chem. Soc. Rev., 2008, 37, 123-150.

9 T. Welton, Chem. Rev., 1999, 99, 2071-2083.

10 A. E. Visser, R. P. Swatloski, W. M. Reichert, S. T. Griffin and R. D. Rogers, Ind. Eng. Chem. Res., 2000, 39, 3596-3604.

11 I. Billard, A. Ouadi, E. Jobin, J. Champion, C. Gaillard and S. Georg, Solvent Extr. Ion Exch., 2011, 29, 577-601. 
12 N. Papaiconomou, G. Vite, N. Goujon, J. M. Leveque and I. Billard, Green Chem., 2012, 14, 2050-2056.

13 Y. Zuo, Y. Liu, J. Chen and D. Q. Li, Ind. Eng. Chem. Res., 2008, 47, 2349-2355.

14 K. Nakashima, F. Kubota, T. Maruyama and M. Goto, Anal. Sci., 2003, 19, $1097-$ 1098.

15 M. P. Jensen, J. Neuefeind, J. V. Beitz, S. Skanthakumar and L. Soderholm, J. Am. Chem. Soc., 2003, 125, 15466-15473.

16 T. Vander Hoogerstraete, B. Onghena and K. Binnemans, J. Phys. Chem. Lett., 2013, 4, 1659-1663.

17 A. Rout, K. A. Venkatesan, T. G. Srinivasan and P. R. Vasudeva Rao, J. Hazard. Mater., 2012, 221, 62-67.

18 I. Billard, A. Ouadi and C. Gaillard, Dalton Trans., 2013, 42, 6203-6212.

19 Y. L. Shen, S. F. Wang, L. Zhu, J. J. Wang and W. S. Wu, Ind. Eng. Chem. Res., 2011, 50, 13990-13996.

20 A. Rout and K. Binnemans, Dalton Trans., 2014, 43, 1862-1872.

21 A. Rout and K. Binnemans, Ind. Eng. Chem. Res., 2014, 53, 6500-6508.

22 A. Fortuny, M. T. Coll and A. M. Sastre, Sep. Purif. Technol., 2012, 97, 137-141.

23 S. Wellens, B. Thijs and K. Binnemans, Green Chem., 2012, 14, 1657-1665. 
24 S. Wellens, R. Goovaerts, C. Möller, J. Luyten, B. Thijs and K. Binnemans, Green Chem., 2013, 15, 3160-3164.

25 T. Vander Hoogerstraete, S. Wellens, K. Verachtert and K. Binnemans, Green Chem., 2013, 15, 919-927.

26 S. Chun, S. V. Dzyuba and R. A. Bartsch, Anal. Chem., 2001, 73, 3737-3741.

27 X. Q. Sun and K. E. Waters, ACS Sustainable Chem. Eng., 2014, 2, 1910-1917.

28 X. Q. Sun, C. L. Do-Thanh, H. M. Luo and S. Dai, Chem. Eng. J., 2014, 239, 392398.

29 Y. Baba, F. Kubota, N. Kamiya and M. Goto, J. Chem. Eng. Jpn., 2011, 44, 679-685.

30 R. P. Swatloski, J. D. Holbrey and R. D. Rogers, Green Chem., 2003, 5, 361-363.

31 M. L. Dietz and J. A. Dzielawa, Chem. Commun., 2001, 2124-2125.

32 M. L. Dietz, J. A. Dzielawa, I. Laszak, B. A. Young and M. P. Jensen, Green Chem., 2003, 5, 682-685.

33 M. P. Jensen, J. A. Dzielawa, P. Rickert and M. L. Dietz, J. Am. Chem. Soc., 2002, 124, 10664-10665.

34 M. L. Dietz and D. C. Stepinski, Green Chem., 2005, 7, 747-750.

35 C. A. Hawkins, S. L. Garvey and M. L. Dietz, Sep. Purif. Technol, 2012, 89, 31-38. 
36 C. Xu, X. H. Shen, Q. D. Chen and H. C. Gao, Science in China Series B-Chemistry, 2009, 52, 1858-1864.

37 S. L. Garvey and M. L. Dietz, Sep. Purif. Technol., 2014, 123, 145-152.

38 H. Luo, S. Dai, P. V. Bonnesen, T. J. Haverlock, B. A. Moyer and A. C. Buchanan, Solvent Extr. Ion Exch., 2006, 24, 19-31.

39 S. L. Garvey, C. A. Hawkins and M. L. Dietz, Talanta, 2012, 95, 25-30.

40 M. L. Dietz, Sep. Sci. Technol., 2006, 41, 2047-2063.

41 C. H. C. Janssen, A. Sanchez, G. J. Witkamp and M. N. Kobrak, ChemPhysChem, 2013, 14, 3806-3813.

42 A. Messadi, A. Mohamadou, S. Boudesocque, L. Dupont and E. Guillon, Sep. Purif. Technol., 2013, 107, 172-178.

43 A. Rout, K. A. Venkatesan, T. G. Srinivasan and P. R. Vasudeva Rao, Sep. Purif. Technol., 2011, 76, 238-243.

44 A. Rout, K. A. Venkatesan, T. G. Srinivasan and P. R. Vasudeva Rao, J. Radioanal. Nucl. Chem., 2011, 290, 215-219.

45 A. Rout, K. A. Venkatesan, T. G. Srinivasan and P. R. Vasudeva Rao, Radiochim. Acta, 2009, 97, 719-725.

46 P. Giridhar, K. A. Venkatesan, T. G. Srinivasan and P. R. Vasudeva Rao, J. Radioanal. Nucl. Chem., 2005, 265, 31-38. 
47 K. Nakashima, F. Kubota, T. Maruyama and M. Goto, Ind. Eng. Chem. Res., 2005, 44, 4368-4372.

48 M. S. Murali, N. Bonville and G. R. Choppin, Solvent Extr. Ion Exch., 2010, 28, 495509.

49 Y. Kikuchi, M. Matsumiya and S. Kawakami, Solvent. Extract. Res. Dev., 2014, 21, 137-145.

50 M. Matsumiya, Y. Kikuchi, T. Yamada and S. Kawakami, Sep. Purif. Technol., 2014, 130, 91-101.

51 D. Q. Li and C. Wang, Hydrometallurgy, 1998, 48, 301-312.

52 W. W. Wang, X. L. Wang, S. L. Meng, H. F. Li and D. Q. Li, J. Rare Earths, 2006, 24, 685-689.

53 I. M. Ahmed, Y. A. El-Nadi and N. E. El-Hefny, Hydrometallurgy, 2013, 131, 24-28.

54 F. J. Alguacil, C. Caravaca, S. Martinez and A. Cobo, Hydrometallurgy, 1994, 36, 369-383.

55 Y. A. El-Nadi, J. Rare Earths, 2010, 28, 215-220.

56 B. Gupta, P. Malik and A. Deep, J. Radioanal. Nucl. Chem., 2002, 251, 451-456.

57 B. Gupta, P. Malik and A. Deep, Solvent Extr. Ion Exch., 2003, 21, 239-258.

58 J. Lu, Z. G. Wei, D. Q. Li, G. X. Ma and Z. C. Jiang, Hydrometallurgy, 1998, 50, 7787. 
59 S. D. Pawar and P. M. Dhadke, Journal of the Serbian Chemical Society, 2003, 68, $581-591$.

60 M. L. P. Reddy, R. L. Varma, T. R. Ramamohan, S. K. Sahu and V. Chakravortty, Solvent Extr. Ion Exch., 1998, 16, 795-812.

61 S. K. Sahu, M. L. P. Reddy, T. R. Ramamohan and V. Chakravortty, Radiochim. Acta, 2000, 88, 33-37.

62 K. Larsson, C. Ekberg and A. Odegaard-Jensen, Hydrometallurgy, 2012, 129, 35-42.

63 E. Dziwinski and J. Szymanowski, Solvent Extr. Ion Exch., 1998, 16, 1515-1525.

64 X. Q. Sun, B. Peng, J. Chen, D. Q. Li and F. Luo, Talanta, 2008, 74, 1071-1074.

65 L. L. Zhu, Y. H. Liu, J. Chen and W. F. Liu, J. Appl. Polym. Sci., 2011, 120, 32843290.

66 X. Q. Sun, D. B. Wu, J. Chen and D. Q. Li, J. Chem. Technol. Biot., 2007, 82, 267272.

67 J. P. Mikkola, P. Virtanen and R. Sojholm, Green Chem., 2006, 8, 250-255.

68 C. Beuchat, D. Hagberg, R. Spezia and L. Gagliardi, J. Phys. Chem. B, 2010, 114, $15590-15597$.

69 X. Q. Sun, Y. Ji, L. Guo, J. Chen and D. Q. Li, Sep. Purif. Technol., 2011, 81, 25-30.

70 W. D. Horrocks and D. R. Sudnick, J. Am. Chem. Soc., 1979, 101, 334-340. 
71 R. M. Supkowski and W. D. Horrocks, Inorg. Chim. Acta, 2002, 340, 44-48.

72 A. Rout, E. R. Souza and K. Binnemans, RSC Adv., 2014, 4, 11899-11906.

73 A. Brandner, T. Kitahara, N. Beare, C. K. Lin, M. T. Berry and P. S. May, Inorg. Chem., 2011, 50, 6509-6520. 